\title{
Time trends in leisure time physical activity and physical fitness in elderly people: 20 year follow- up of the Spanish population national health survey (1987-2006)
}

Domingo Palacios-Ceña ${ }^{1,3^{*}}$, Cristina Alonso-Blanco ${ }^{1}$, Rodrigo Jiménez-Garcia ${ }^{2}$, Valentin Hernández-Barrera ${ }^{2}$, Pilar Carrasco-Garrido², Elena Pileño-Martinez ${ }^{1}$ and Cesar Fernández-de-las-Peñas ${ }^{4}$

\begin{abstract}
Background: To estimate trends in leisure time physical activity and physical fitness between 1987-2006 in older Spanish people.

Methods: We analyzed data collected from the Spanish National Health Surveys conducted in 1987 ( $n=29,647$ ), $1993(n=20,707), 1995-1997(n=12,800), 2001(n=21,058), 2003(n=21,650)$, and $2006(n=29,478)$. The number of subjects aged $\geq 65$ years included in the current study was 29,263 (1987: $n=4,958-16.7 \% ; 1993: n=3,751$ 17.8\%; 1995-97: $n=2,229-17.4 \% ; 2001: n=4,356-20.7 \% ; 2003: 6,134-28.3 \% ; 2006:$ 7,835-26.5\%). Main variables included leisure-time physical activity and physical fitness. We analyzed socio-demographic characteristics, self-rated health status, lifestyle habit and co-morbid conditions using multivariate logistic regression models.

Results: Women exhibited lower prevalence of leisure time physical activity and physical fitness compared to men $(P<0.05)$. The multivariate analysis for time trends found that practising leisure time physical activity increased from 1987 to $2006(P<0.001)$. Variables associated with a lower likelihood of practicing leisure time physical activity were: age $\geq 80$ years old, $\geq 2$ co-morbid chronic conditions, and obesity. Variables associated with lower physical fitness included: age $\geq 80$ years, worse self rated health; $\geq 2$ medications (only for walking), and obesity.

Conclusions: We found an increase in leisure time physical activity in the older Spanish population. Older age, married status, co-morbid conditions, obesity, and worse self-perceived health status were associated with lower activity. Identification of these factors can help to identify individuals at risk for physical inactivity.
\end{abstract}

\section{Background}

In recent years, there has been an increase of aging in the society [1]. The aging of the population can lead to an increase in the number of individuals at risk for chronic diseases [2]. In an article from the Center for Disease Control and Prevention's Healthy Aging Network, physical activity (PA) was considered one key element for determining health status [3]. Recent guidelines include PA recommendations for older people [4] because regular PA can provide health benefits, even when it is initiated later in life [5]. In fact, evidence

\footnotetext{
* Correspondence: domingo.palacios@urj.es

'Department of Health Science II, Universidad Rey Juan Carlos, Madrid, Spain Full list of author information is available at the end of the article
}

suggests that PA is associated with more years of life, self-perceived healthy life, years without impairment in daily live activities [6], lower rates of functional decline [7], lower risk of mortality [8,9], increased longevity $[6,10]$, reduced risk of type 2 diabetes [11], and better quality of life [12].

Physical activity is defined as any bodily movement produced by skeletal muscles that result in energy expenditure [13]. Nevertheless, physical activity is a broad term that encompasses both leisure-time activity (sports, exercise) [13] and activities of daily life [13,14]. Leisure time physical activity (LTPA) refers to conditioning exercise or sports not related to regular work activities $[13,15]$. Walking is the most common form of

\section{Ciomed Central}


physical activity and is recommended for all ages [16-18]. Physical fitness is defined as a set of attributes that people have or achieve that relates to the ability to perform physical activity [13]. In fact, different studies have used walking and walking up-stairs to evaluate physical fitness of older people $[19,20]$. However, PA research has mainly focused on middle-aged and the elderly combined [17,21-28]. In fact, few studies have investigated PA only in older people [14,16,29-33].

Studies conducted in the USA [28], Australia [21], England [27] and Scotland [22] had reported a trend towards an increased PA in individuals older than 60 years of age. In fact, the increase in PA has been found to be higher in people older than 65 years than in middle-aged population $[17,25,33]$. Nevertheless, some authors have suggested the opposite, that older people report lower PA $[21,23,26]$. In line with this hypothesis, the Center for Disease Control [24] reported that the prevalence of LTPA declined from $29.8 \%$ in 1994 to $23.7 \%$ in 2007 in the United States.

In Spain, more than $40 \%$ of older adults are sedentary [34-37]. Although the percentage of people who practice LTPA has increased [36], more information is needed to understand factors that facilitate or inhibit older people tendency to engage in LTPA. Previous studies conducted in older adults have reported that important variables for PA include those potentially handled from public health and social-educational policies: gender $[16,29,33]$, age $[16,22,29]$, educational level [14,32,33], monetary income $[14,17,32]$, marital status [29], co-morbid diseases [16,17,29], alcohol consumption [16,17], smoking $[17,29]$, self-perceive health $[30,33]$, and obesity $[14,22,31]$

No previous study has examined the time trends of physical activity in the last 20 years in older Spanish people. Therefore, the current study examines time trends in prevalence of PA for adults aged 65 and over using Spanish National Health Surveys (SNHS) conducted in the period 1987-2006. The objectives of this study were: 1) to describe the prevalence of LTPA and physical fitness among the Spanish elderly population in the period 1987-2006; 2) to determine socio-demographic features, self-perceived health status, co-morbidity, and lifestyle-related habits associated with LTPA and physical fitness in older people; and, 3) to analyze time trends in prevalence of LTPA and physical fitness in the period 1987-2006 in Spanish older people.

\section{Methods}

\section{Ethical aspects}

As this analysis was conducted on a de-identified, public-use dataset it was not necessary to have the approval of an ethics committee according to Spanish legislation.

\section{The Spanish National Health Surveys (SNHS)}

We conducted a cross-sectional study using individualized data obtained from the SNHS done in 1987, 1993, 1995, 1997, 2001, 2003, and 2006. The SNHS is an ongoing, home-based personal interview examining a national representative sample of non-institutionalized population residing in main family dwellings (households) of Spain and is mainly performed by the Ministry of Health and Consumer Affairs and the National Statistics Institute (Instituto Nacional Estadística-INE). The SNHS uses a multistage cluster sampling, with proportional random selection of primary and secondary sampling units (towns and sections, respectively), with the final units (individuals) being selected by means of random routes and sex- and age-based quotas.

Surveyors were previously trained about basic communication skills, procedures and the used questionnaire. Informed consent was signed by all participants before they answered the survey. In order to meet the surveys' stated aim of being able to furnish estimates with a certain degree of reliability at both national and regional levels the following samples of adult aged 15 years and older were selected in the SNHS: 29,647 in 1987; 20,707 in 1993; 21,058 in $2001 ; 21,650$ in 2003; and 29,478 in 2006. Surveys conducted in 1995 and 1997 were based on smaller sample sizes $(\mathrm{N}=6,400)$, therefore these two databases were joined and analyzed together. The number of subjects aged $\geq 65$ years included in the study along the entire period was 29,263 (1987: $\mathrm{n}=4,958$ $16.7 \% ; 1993: \mathrm{n}=3,751-17.8 \% ; 1995-97: \mathrm{n}=2,229-17.4 \%$; 2001: $n=4,356-20.7 \% ; 2003: 6,134-28.3 \% ; 2006: 7,835-$ $26.5 \%)$. More details about the SNHS methodology are described elsewhere [38,39].

For the purpose of the current study, we included answers from adults aged 65 years and older from these 7 SNHS. The variables included in the current study were created on the basis of several questions included in the questionnaires and identical in all surveys. The dependent variables were: 1, LTPA, which was collected using the following question: "Do you practice any physical activity during your leisure time?", with 2 possible answers: "none" or "once a month or more", and 2, physical daily fitness, which was assessed with 2 questions: "Can you walk up 10 steps without help?" and, "Can you keep walking for one hour without rest?." The answer to both questions could be "yes" or "no". These last two questions were first collected within the 1993 survey.

We also analyzed socio-demographic characteristics such as age (65 to 79 years, 80 years and older), marital status (married or living as a couple, unmarried/widow/ divorced), and educational level (no study, primary education completed, secondary education, or more). 
Self-perceived health status was assessed with the following question: "How did you self-perceive your health status over the previous 12 months?" Subjects described their health status as very good, good, fair, poor, very poor. The answer was dichotomized into very good/ good or fair/poor/very poor self-perceived health status. We also collected the number of medical doctor diagnoses of co-morbid chronic conditions (high blood pressure, diabetes, chronic heart disease, chronic bronchitis, emphysema, or asthma) as follows: none, one, two, or more. The number of prescribed medications for any of these chronic conditions was also categorized as none, one, two or more. Body mass index (BMI) was calculated from self-reported body weight and height. Individuals with a BMI $\geq 30$ were classified as obese, those with BMI between 25 and 29.9 were classified as overweight and those with $\mathrm{BMI}<25$ were considered to have normal weight. Individuals with $\mathrm{BMI}<18.5$ or incomplete data on height and weight were excluded for the analysis.

Regarding lifestyle habits, smoking habits differentiated between current smokers, non-smokers or exsmokers. Finally, sleep habits were divided into subjects sleeping $>8$ hours per day and those sleeping $<8$ hours per day.

\section{Statistical analysis}

In this study we analyzed physical activity and physical fitness separately for men and women and we excluded respondents with missing data for any outcome. We calculated descriptive measures for all variables of interest by aged-group and SNHS. Second, we compared the reported prevalence for the dependent variables and age group according to the SNHS. Third, we fit logistic regression models by gender to assess factors independently associated for each dependent variable. Finally, to evaluate the time trend across the period 1987-2006, adjusted odds ratios (ORs) with their confidence intervals were estimated using multivariate logistic regression models. Models were initially adjusted by age and by those variables that yield significant associations within the bivariate analysis. We assessed significant interaction terms in fully adjusted models; for significant effects, we stratified the fully adjusted models by the relevant factor. The estimates were made using the "svy" (survey command) functions of the STATA program, which allowed us to incorporate the study design and weights in all our statistical calculations. Statistical significance was established at $\mathrm{P}<0.05$ (two-tailed $\mathrm{P}$ values).

\section{Results}

The mean age increased significantly from 72.3 to 74.8 years for women and from 72.2 to 74.5 years for men across the study period $(\mathrm{P}<0.05)$. Women were slightly, but significantly older than men in all surveys $(\mathrm{P}<0.05)$. Tables 1, 2 summarize the distribution by socio-demographic characteristics and health related variables among women and men according to the SNHS conducted (1987 2006).

Among women, the prevalence of those married, higher education, higher number of chronic conditions and medications, obesity and smoking habit significantly increased along the period 1987-2006 ( $\mathrm{P}<0.01$ ). Among men, the evolution was very similar to women except for smoking habits that decreased from $33.8 \%$ to $15.4 \%$ $(\mathrm{P}<0.01)$.

Time trends for LTPA, capacity to walk up ten steps without help and to walk for one hour without rest by aged-group and gender are summarized in Table 3 . Overall, women exhibited lower prevalence of LTPA and physical fitness (in both variables) as compared to men in all surveys $(\mathrm{P}<0.01)$. In both gender, the prevalence for all dependent variables were always higher in the younger aged group. The highest prevalence of LTPA was found for both genders in the SNHS conducted in 2006 , with $54.6 \%$ for women, and $69.6 \%$ for men, respectively $(\mathrm{P}<0.05)$.

Crude time trends analysis by aged-group and gender revealed an increase in the prevalence of LTPA over time among women and men in all aged-groups $(\mathrm{P}<$ 0.001). On the contrary, no significant changes for physical fitness during the time period by gender or agedgroup were found $(\mathrm{P}>0.05)$.

The multivariate analysis for time trends in women found that LTPA increased significantly from 1987 to 2006 ( $\mathrm{P}<0.001$, Figure 1$)$. In addition, time trends (1993-2006) for the variable walking for one hour, but not for walking 10 steps without help (Figure 2) also exhibited a significant improvement $(\mathrm{P}<0.01$, Figure 3$)$. The results of the multivariate analysis to estimate time trends and associated factors for older women are summarized in the table 4. Further, variables significantly associated with a lower likelihood of reporting LTPA among women were: age $\geq 80$ years, $\geq 2$ co-morbid chronic conditions, and obesity. Variables associated with not being able to walk up ten steps or walking for one hour included: age $\geq 80$ years, worse self-rated health, $\geq 2$ medications (only for walking for one hour) and again obesity.

Among men, LTPA has also significantly increased from 1987 to 2006 ( $<<0.001$, Figure 1$)$, but no significant changes for physical fitness were observed (Figures $2,3)$. The results of the multivariate analysis to estimate time trends and associated factors for older men are found within table 5 . Factors associated to less practicing LTPA in men were: age $\geq 80$ years, being married, and obesity. Variables associated with worse physical fitness among men were the same as for women: age 80 
Table 1 Frequencies Statistic for WOMEN: Spanish National Health Surveys (SNHS) 1987, 1993, 1995-7, 2001, 2003 and 2006

\begin{tabular}{|c|c|c|c|c|c|c|c|}
\hline & & SNHS 1987 & SNHS 1993 & SNHS 95-97 & SNHS 2001 & SNHS 2003 & SNHS 2006 \\
\hline & & $\mathrm{N}=2,846$ & $\mathrm{~N}=2,137$ & $N=1,303$ & $\mathrm{~N}=2,494$ & $\mathrm{~N}=3,830$ & $N=5,022$ \\
\hline Age Mean $(\mathrm{SE})^{+}$ & & $72.3(0.15)$ & $74.3(0.23)$ & $72.6(0.17)$ & $73.0(0.14)$ & $74.7(0.16)$ & $74.8(0.14)$ \\
\hline \multirow[t]{2}{*}{ Age group $^{+}$} & $65-79$ & 85.5 & 84.5 & 84.9 & 83.6 & 76.2 & 75.5 \\
\hline & $\geq 80$ & 14.5 & 15.5 & 15.1 & 16.4 & 23.8 & 24.5 \\
\hline \multirow[t]{2}{*}{ Marital status* } & Unmarried/widow/divorced & 54.0 & 47.9 & 49.8 & 47.5 & 50.9 & 49.4 \\
\hline & Married or living with couple & 46.0 & 52.1 & 50.2 & 52.5 & 49.1 & 50.6 \\
\hline \multirow[t]{3}{*}{ Educational level* } & No studies & 72.9 & 49.7 & 38.9 & 26.5 & 42.0 & 42.0 \\
\hline & Primary education completed & 21.7 & 42.7 & 55.2 & 67.2 & 46.3 & 45.2 \\
\hline & Secondary education or more & 5.4 & 7.6 & 5.9 & 6.3 & 11.7 & 12.8 \\
\hline \multirow[t]{2}{*}{ Self rated health } & Very good/good & 34.6 & 39.4 & 37.0 & 36.5 & 33.0 & 33.1 \\
\hline & Fair/poor/very poor & 65.4 & 60.6 & 63.0 & 63.5 & 67.0 & 66.9 \\
\hline \multirow[t]{3}{*}{ Na of chronic conditions* } & None & 40.8 & 41.3 & 37.6 & 32.9 & 26.8 & 19.0 \\
\hline & 1 & 31.8 & 33.0 & 32.3 & 33.2 & 33.2 & 32.7 \\
\hline & $\geq 2$ & 27.4 & 25.7 & 30.1 & 33.9 & 40.0 & 48.3 \\
\hline \multirow[t]{3}{*}{ Number of medications* } & None & 26.7 & 26.1 & 19.0 & 15.4 & 9.1 & 6.5 \\
\hline & 1 & 34.5 & 33.6 & 33.1 & 31.2 & 21.4 & 14.7 \\
\hline & $\geq 2$ & 38.8 & 40.3 & 47.9 & 53.4 & 69.5 & 78.8 \\
\hline \multirow[t]{3}{*}{$\mathrm{BMl}^{*}$} & Normal & 41.6 & 39.1 & 49.7 & 31.2 & 35.2 & 31.5 \\
\hline & Overweight & 41.9 & 43.4 & 31.4 & 41.8 & 42.3 & 42.4 \\
\hline & Obesity & 16.5 & 17.5 & 18.9 & 27.0 & 22.5 & 26.1 \\
\hline \multirow[t]{3}{*}{ Smoking habits* } & Smoker & 1.9 & 3.9 & 1.7 & 2.2 & 1.7 & 3.1 \\
\hline & Ex Smoker & 2.7 & 2.5 & 2.4 & 2.9 & 2.9 & 4.5 \\
\hline & Non Smoker & 95.4 & 93.6 & 95.9 & 94.9 & 95.4 & 92.4 \\
\hline \multirow[t]{2}{*}{ Sleep habits (hours day) } & $<8$ & 45.8 & 48.2 & 41.9 & 42.8 & 44.8 & 46.8 \\
\hline & $\geq 8$ & 54.2 & 51.8 & 58.1 & 57.2 & 55.2 & 53.2 \\
\hline
\end{tabular}

Data are expressed as percentages (\%)

+ Significant differences between SNHS/*Significant differences between SNHS (adjusted by age)

years or over, worse self-rated health, $\geq 2$ medications, and obesity (only for walking for one hour).

\section{Discussion}

Our study revealed an increase in LTPA from 1987 to 2006 in older Spanish people. The results are consistent with studies conducted in European, American and Asian countries [22,25,27]. In Spain, the study conducted by Roman-Viñas et al [40] observed a slight decreased in the proportion of sedentary leisure time activities for males (from $50 \%$ to $45 \%$ ) and females (from $67 \%$ to 63\%). However, this study was conducted in Catalonia, a region of Spain, and did not focus in LTPA in older people $[40,41]$. Therefore, our study is the first one that includes national data over a period of 20 years in the Spanish older population.

The Scottish Health Survey found an increase in PA among older people aged between 65 to 74 years, but a decline in walking (65-74 year) and training sports among 75 years and over [22]. The results derived from the Health Survey in England (1991-2004) found an upward trend in regular sports participation in all age groups, but particularly pronounced among the older groups ( $\geq 65$ years) [27]. The Behavioral Risk Factors Surveillance System found an increase in the prevalence of walking from 1987 to 2000, particularly in older people [28]. The Japan Collaborative Cohort Study also showed an increase in sports and physical exercise in subjects aged 50-79 years old [25]. Previous studies have shown a tendency that decreased activity occurs with increasing age $[14,24,31]$; however, a cross-sectional study conducted with Chinese women found that older age was positively associated with participation in exercise/sports and walking [17].

We have also found that women exhibit lower prevalence of LTPA and physical fitness as compared to men in all surveys, which is in agreement with the results by Stamatakis et al [27]. The Cardiovascular Health Study showed that men were more active in LTPA than women in all age groups [6], which also agree with the 
Table 2 Frequencies Statistic for MEN: Spanish National Health Surveys (SNHS) 1987, 1993, 1995-7, 2001, 2003 and 2006

\begin{tabular}{|c|c|c|c|c|c|c|c|}
\hline & & SNHS 1987 & SNHS 1993 & SNHS 95-97 & SNHS 2001 & SNHS 2003 & SNHS 2006 \\
\hline & & $\mathrm{N}=2,112$ & $N=1,614$ & $N=926$ & $N=1,862$ & $\mathrm{~N}=2,304$ & $\mathrm{~N}=2,813$ \\
\hline${\text { Age Mean }(\mathrm{SE})^{+}}^{+}$ & & $72.2(0.18)$ & $74.9(0.28)$ & $73.3(0.21)$ & $73.3(0.16)$ & $73.8(0.19)$ & $74.5(0.16)$ \\
\hline \multirow[t]{2}{*}{ Age group $^{+}$} & $65-79$ & 85.3 & 84.7 & 84.6 & 84.4 & 80.5 & 77.3 \\
\hline & $\geq 80$ & 14.7 & 15.3 & 15.4 & 15.6 & 19.5 & 22.7 \\
\hline \multirow[t]{2}{*}{ Marital status } & Unmarried/widow/divorced & 20.8 & 22.7 & 20.2 & 19.4 & 19.0 & 20.0 \\
\hline & Married or living with couple & 79.2 & 77.3 & 79.8 & 80.6 & 81.0 & 80.0 \\
\hline \multirow[t]{3}{*}{ Educational level* } & No studies & 57.9 & 32.3 & 34.7 & 21.2 & 34.8 & 30.4 \\
\hline & Primary education completed & 29.7 & 49.9 & 52.6 & 66.3 & 44.5 & 45.5 \\
\hline & Secondary education or more & 12.4 & 17.8 & 12.7 & 12.5 & 20.7 & 24.1 \\
\hline \multirow[t]{2}{*}{ Self rated health* } & Very good/good & 45.0 & 48.4 & 44.5 & 47.6 & 44.9 & 48.5 \\
\hline & Fair/poor/very poor & 55.0 & 51.6 & 55.5 & 52.4 & 55.1 & 51.5 \\
\hline \multirow[t]{3}{*}{$\mathrm{Na}^{\mathrm{a}}$ of chronic conditions* } & None & 44.5 & 47.4 & 40.9 & 35.6 & 33.0 & 21.6 \\
\hline & 1 & 32.3 & 34.2 & 33.9 & 33.7 & 33.5 & 32.3 \\
\hline & $\geq 2$ & 23.2 & 18.4 & 25.2 & 30.7 & 33.5 & 46.1 \\
\hline \multirow[t]{3}{*}{ Number of medications* } & None & 37.7 & 36.4 & 26.3 & 22.1 & 15.0 & 12.3 \\
\hline & 1 & 35.0 & 37.7 & 37.0 & 34.1 & 30.6 & 22.8 \\
\hline & $\geq 2$ & 27.3 & 25.9 & 36.7 & 43.8 & 54.4 & 64.9 \\
\hline \multirow[t]{3}{*}{$\mathrm{BMI}^{*}$} & Normal & 45.1 & 37.8 & 40.3 & 30.9 & 27.7 & 28.0 \\
\hline & Overweight & 44.5 & 48.1 & 45.1 & 51.8 & 53.1 & 51.0 \\
\hline & Obesity & 10.4 & 14.1 & 14.6 & 17.3 & 19.2 & 21.0 \\
\hline \multirow[t]{3}{*}{ Smoking habits* } & Smoker & 33.8 & 27.9 & 24.2 & 19.3 & 16.8 & 15.4 \\
\hline & Ex Smoker & 43.3 & 43.9 & 50.0 & 53.1 & 52.2 & 54.3 \\
\hline & Non Smoker & 22.9 & 28.2 & 25.8 & 27.6 & 31.0 & 30.3 \\
\hline \multirow[t]{2}{*}{ Sleep habits (hours/day) } & $<8$ & 59.5 & 57.3 & 56.8 & 52.3 & 61.0 & 58.0 \\
\hline & $\geq 8$ & 40.5 & 42.7 & 43.2 & 47.7 & 39.0 & 42.0 \\
\hline
\end{tabular}

Data are expressed as percentages (\%)

+ Significant differences between SNHS/*Significant differences between SNHS (adjusted by age)

current results. Contrary, Simpson et al. [28] have shown a higher prevalence of elder women who walk. In this study, women were two to three times more likely than men to report that walking was one of their LTPA.

The decreased prevalence of LTPA among women can be attributed to monitorization of daily transports [26]. Gallant and Dorn [42] have reported that social network emerged more importantly for women than for men, which indicates that women may perform many of health behaviors within a social context [43]. The omission of household activities may underestimate the total PA within women and result in misclassified as physically not very active [26]. Further, cultural perspectives can influence LTPA [44]. In fact, Spanish people have a poor attitude to change or improve their physical activity as compared to Europeans [45]. In Spain, gender differences in LTPA are in accordance with findings previously reported by Cornelio et al [41].

We found that age $\geq 80$ years, to be married, $\geq 2$ comorbid chronic conditions and obesity were associated with a lower likelihood of reporting LTPA in both genders, which is in agreement with previous studies conducted in Australia [16] and USA [29]. Gallant and Dorn [42] reported that marital status showed an influential element in men's health behavior. Our results are also consistent with Kaplan et al [29] who found that married subjects were less likely to be active than single, widowed, or divorced.

The current study also found that education level (primary or over) was related with LTPA and fitness activity, which agrees with previous studies $[14,17,32]$. The Shanghai Women's Health Study reported that women aged 40-70 years of age with more education were more likely to practice sports, but widows/divorced/separated were more likely to walk [17]. In contrast, Wong et al reported that people with lower educational level spent more time on walking than those with higher level [32].

Among behavioral factors, smoking and BMI $>28$ were negatively associated with LTPA. These results agree with previous studies showing that obesity was 
Table 3 Time trends by gender and age group in leisure time physical activity and physical fitness between 1987 and 2006

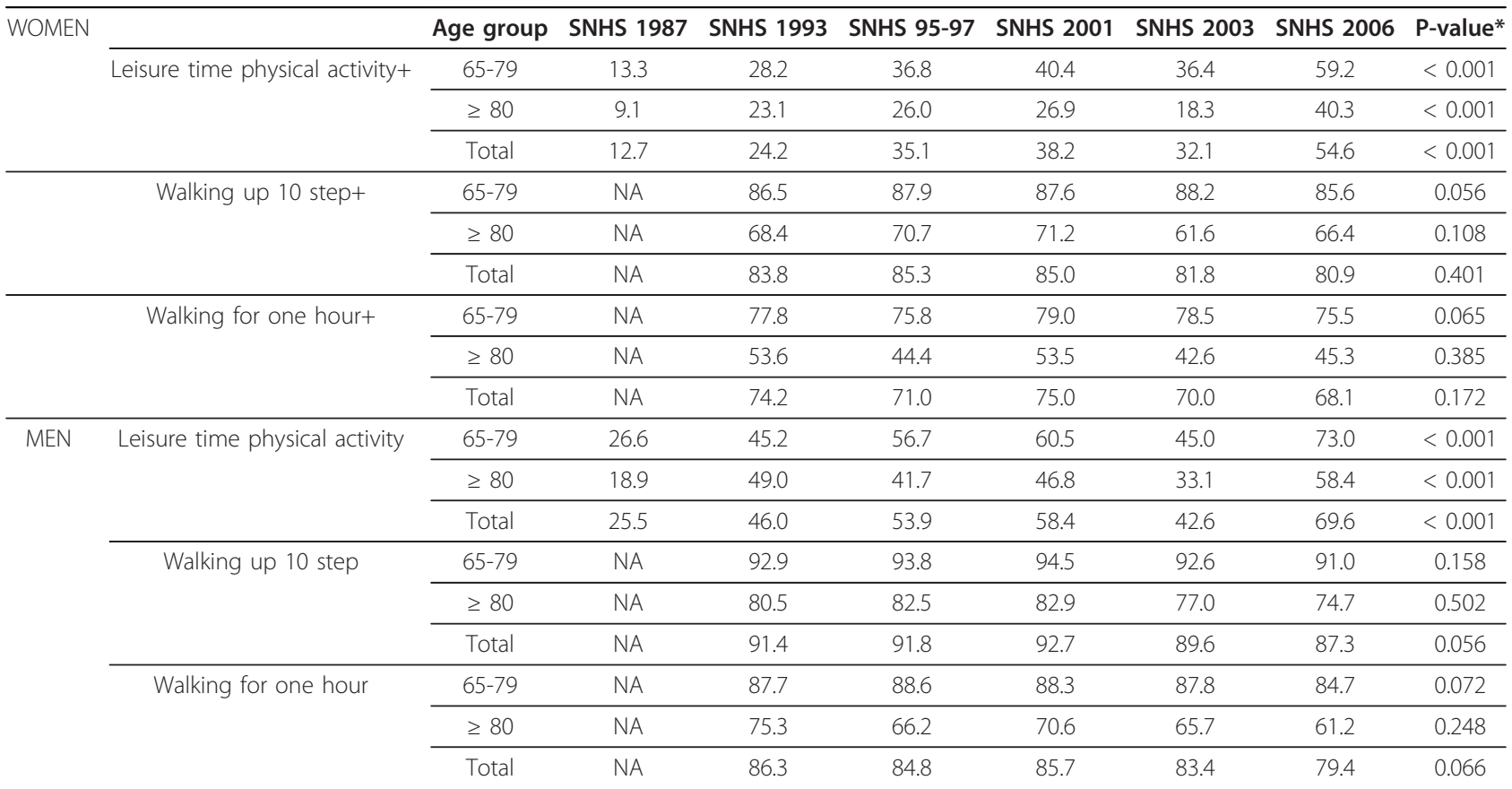

$\mathrm{P}$ value for association between the prevalence of study variables and the SNHS (multivariate regression models)/NA: Not available.

+ Significant differences in the total prevalence of study variables between women and men

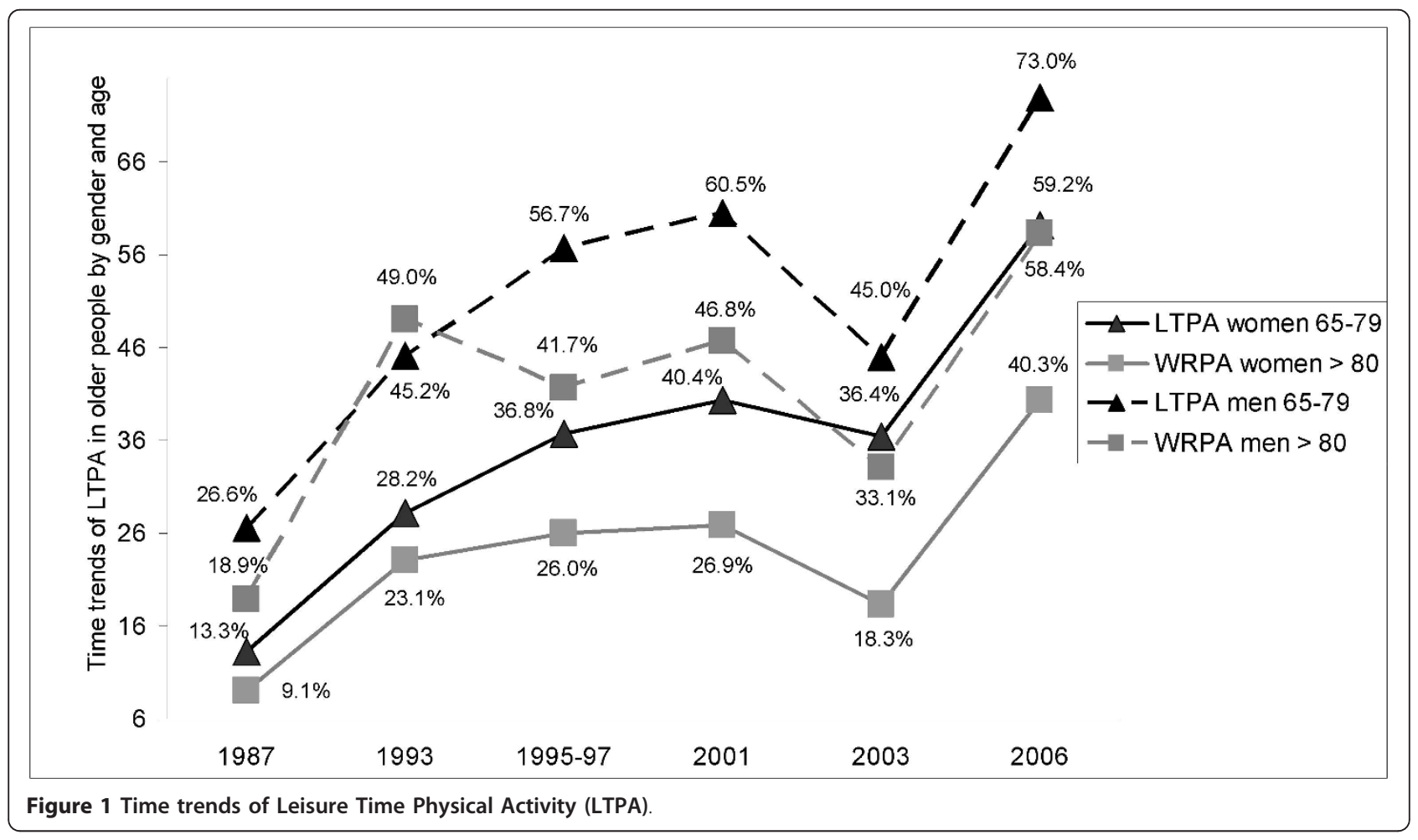




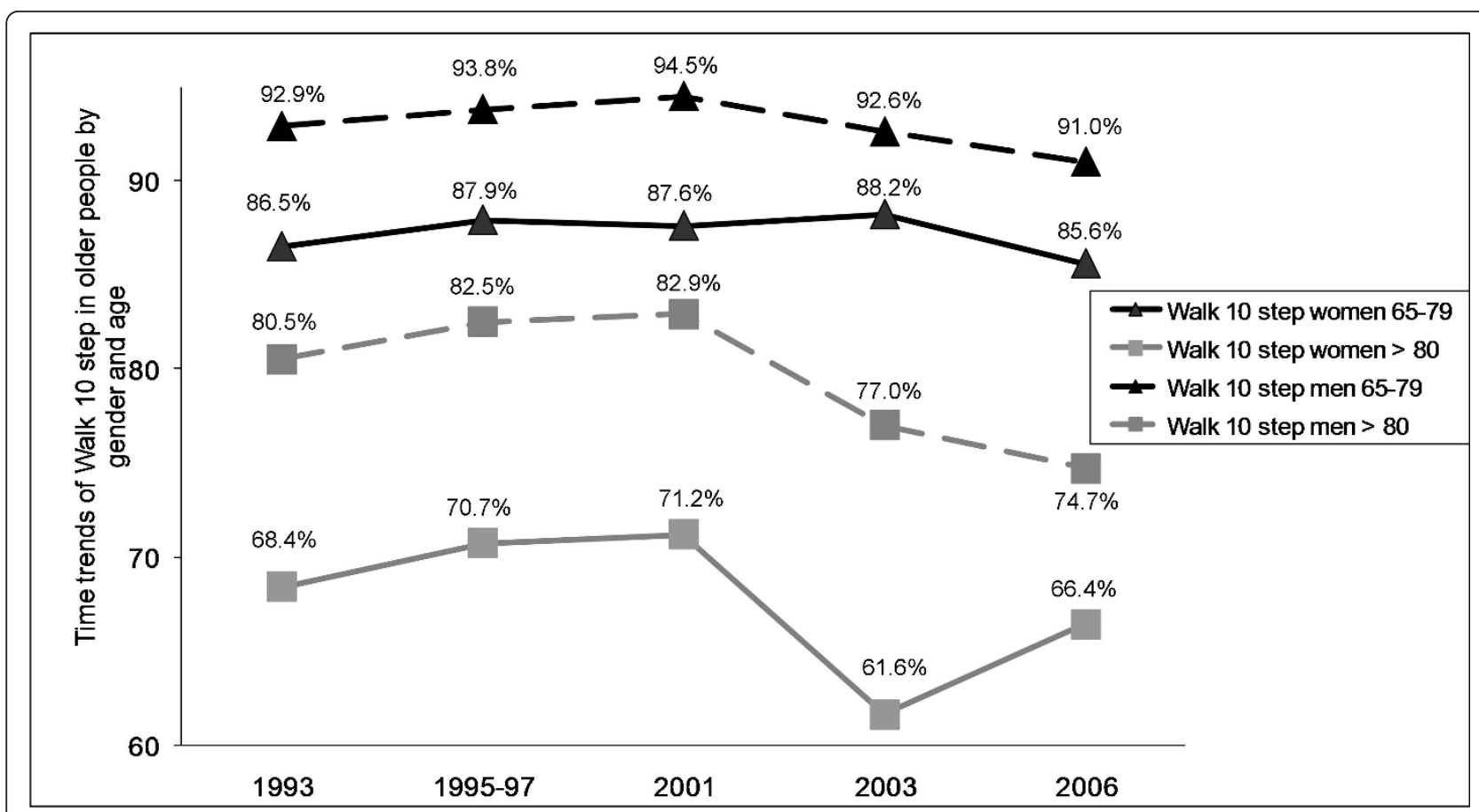

Figure 2 Time trends of Walk 10 steps.

associated with lower activity $[22,46]$. In the longitudinal analyses of the CHIANTI study, obese older population with low muscle strength had steeper decline in walking speed, walk $400 \mathrm{~m}$ or climb one flight on stairs as compared with those without obesity or low muscle strength [47]. Spanish sedentary older people exhibited lower education level in both genders. Sedentary men consume alcohol less frequently and have a higher number of chronic diseases than women, while sedentary older women are obese, have never smoked

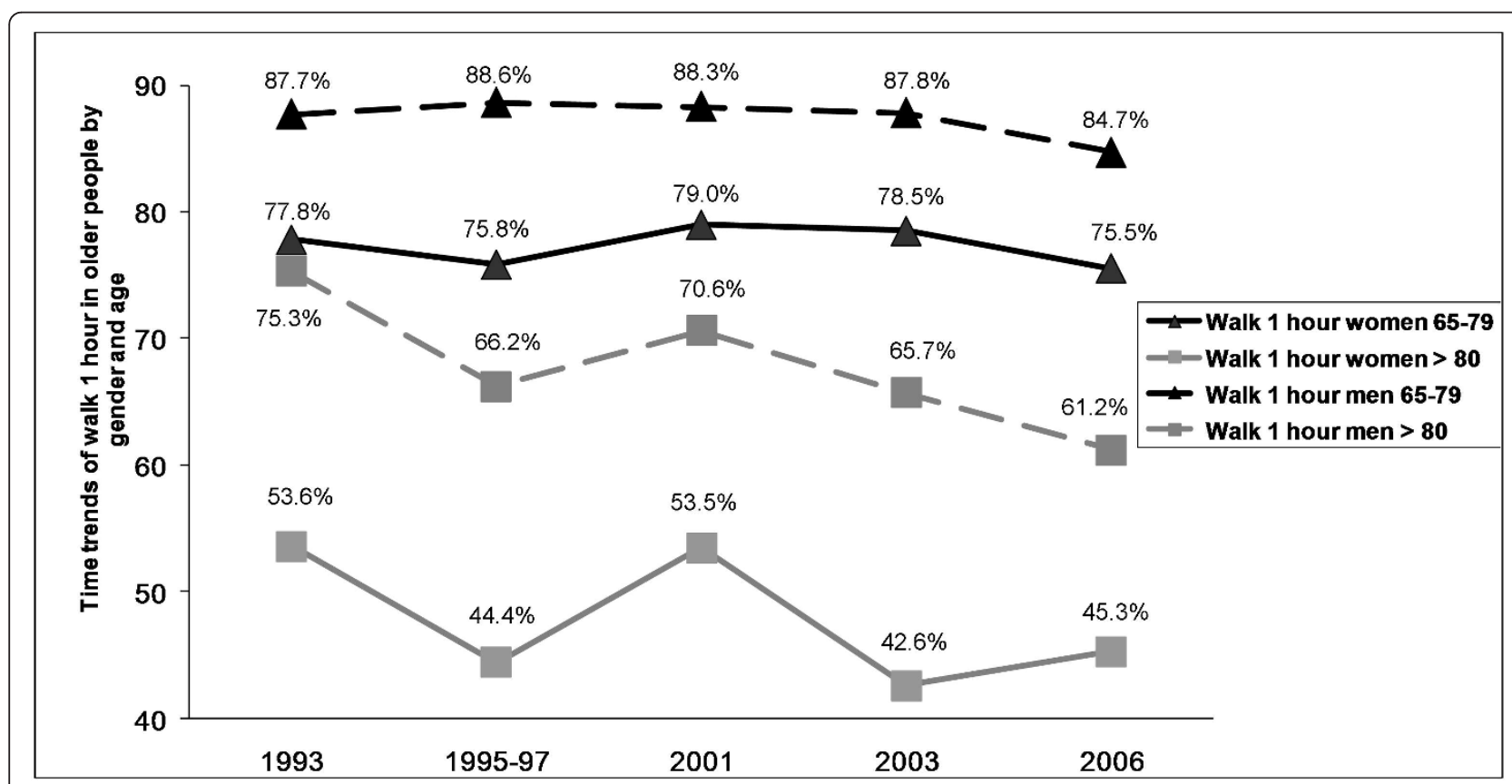

Figure 3 Time trends of Walk 1 hour. 
Table 4 Logistic Regression Models for WOMEN

\begin{tabular}{|c|c|c|c|c|}
\hline & & Leisure time physical activity & Walking up 10 step & Walking for one hour \\
\hline \multirow[t]{2}{*}{ Age group } & $65-79$ & 1 & 1 & 1 \\
\hline & $\geq 80$ & $0.43(0.36-0.51)$ & $0.27(0.22-0.34)$ & $0.23(0.19-0.28)$ \\
\hline \multirow[t]{2}{*}{ Marital status } & Unmarried/widow/divorced & 1 & 1 & 1 \\
\hline & Married or living with couple & $0.87(0.75-1.00)$ & $1.29(1.06-1.58)$ & $1.41(1.19-1.66)$ \\
\hline \multirow[t]{3}{*}{ Educational level } & No studies & 1 & 1 & 1 \\
\hline & Primary education completed & $1.15(0.99-1.33)$ & $1.64(1.34-2.00)$ & $1.28(1.08-1.51)$ \\
\hline & Secondary education or more & $1.13(0.90-1.42)$ & $1.48(1.05-2.08)$ & $1.28(0.97-1.68)$ \\
\hline \multirow[t]{2}{*}{ Self rated health } & Very good/good & 1 & 1 & 1 \\
\hline & Fair/poor/very poor & $1.13(0.97-1.32)$ & $0.22(0.16-0.29)$ & $0.19(0.16-0.24)$ \\
\hline \multirow[t]{3}{*}{$\mathrm{Na}^{\mathrm{a}}$ of chronic conditions } & None & 1 & 1 & 1 \\
\hline & 1 & $0.89(0.74-1.08)$ & $1.50(1.11-2.04)$ & $1.33(1.04-1.71)$ \\
\hline & $\geq 2$ & $0.74(0.61-0.89)$ & $1.19(0.90-1.57)$ & $0.93(0.74-1.17)$ \\
\hline \multirow[t]{3}{*}{ Number of medications } & None & 1 & 1 & 1 \\
\hline & 1 & $1.28(0.96-1.72)$ & $1.02(0.56-1.84)$ & $0.83(0.52-1.30)$ \\
\hline & $\geq 2$ & $1.15(0.87-1.53)$ & $0.58(0.33-1.02)$ & $0.48(0.31-0.72)$ \\
\hline \multirow[t]{3}{*}{ BMI } & Normal & 1 & 1 & 1 \\
\hline & Overweight & $0.98(0.84-1.15)$ & $0.99(0.79-1.27)$ & $0.97(0.79-1.18)$ \\
\hline & Obesity & $0.77(0.63-0.95)$ & $0.60(0.46-0.77)$ & $0.56(0.45-0.70)$ \\
\hline \multirow[t]{3}{*}{ Smoking habits } & Smoker & 1 & 1 & 1 \\
\hline & Ex Smoker & $1.03(0.60-1.77)$ & $0.59(0.24-1.45)$ & $1.20(0.60-2.42)$ \\
\hline & Non Smoker & $1.37(0.90-20.7)$ & $0.51(0.25-1.04)$ & $0.86(0.50-1.48)$ \\
\hline \multirow[t]{2}{*}{ Sleep habits (hours/day) } & $<8$ & 1 & 1 & 1 \\
\hline & $\geq 8$ & $1.01(0.88-1.15)$ & $1.19(0.99-1.43)$ & $1.35(1.15-1.58)$ \\
\hline \multirow[t]{6}{*}{ SNHS } & 1987 & 1 & - & - \\
\hline & 1993 & $1.82(1.40-2.36)$ & 1 & 1 \\
\hline & $1995-97$ & $2.82(2.15-3.70)$ & $0.98(0.65-1.49)$ & $1.44(1.02-2.05)$ \\
\hline & 2001 & $3.66(2.86-4.67)$ & $1.15(0.78-1.69)$ & $1.70(1.24-2.34)$ \\
\hline & 2003 & $2.53(1.99-3.21)$ & $1.20(0.84-1.72)$ & $1.59(1.19-2.13)$ \\
\hline & 2006 & $3.69(2.89-4.70)$ & $1.29(0.90-1.86)$ & $1.63(1.21-2.19)$ \\
\hline
\end{tabular}

The results of the logistic models are shown as adjusted odds ratios (ORs) with $95 \%$ confidence intervals. Models adjusted by all variables shown in the table, no significant interactions were found

and consumed more frequently 3 or more drugs than men [34].

Our results provide evidence that older people reporting a fair/poor/very poor self-rated health status have difficulties in walking and climbing stairs. Self-perceived health status is considered as a reliable predictor of PA, walking decline and mortality in older people [6]. In fact, perceived poor health status has been associated with lower PA [33], as PA significantly correlates with self-reported health in older adults [48].

Our study has revealed an increase in LTPA during the last 20 years, but not for the capacity to walk up ten steps or walk for one hour. The tendency to respond affirmatively to LTPA can be explained because older people sometimes have a negative opinion of those inactive, and have their own beliefs about the effects of PA [49]. In addition, the less active older individual tends to underestimate the benefits of exercise [50]. This may be related to the fact that this group is determined by antiaging messages that appear in mass media [51], social [42] and cultural contexts [44]. They may have a tendency to integrate socially, avoiding showing they need help for anything [52]. In addition, elders may overestimate the PA [18] which they practiced, or be unaware of the recommendations or levels of exercise for effective results [14]. Other factors that may influence adherence to PA in the elderly are outcome expectations and environmental barriers [53], self-efficacy [54]. It is also possible that older people meet the PA recommendations to maintain their health status but at the same time have a sedentary lifestyle, and therefore their physical fitness has not improved.

Finally, we should recognize some limitations of our study. First, discrepancies between trends of increase or 
Table 5 Logistic Regression Models for MEN

\begin{tabular}{|c|c|c|c|c|}
\hline & & Leisure time physical activity & Walking up 10 step & Walking for an hour \\
\hline \multirow[t]{2}{*}{ Age group } & $65-79$ & 1 & 1 & 1 \\
\hline & $\geq 80$ & $0.61(0.49-0.75)$ & $0.37(0.28-0.49)$ & $0.30(0.24-0.39)$ \\
\hline \multirow[t]{2}{*}{ Marital status } & Unmarried/widow/divorced & 1 & 1 & 1 \\
\hline & Married or living with couple & $0.79(0.65-0.95)$ & $0.74(0.54-1.02)$ & $0.94(0.73-1.22)$ \\
\hline \multirow[t]{3}{*}{ Educational level } & No studies & 1 & 1 & 1 \\
\hline & Primary education completed & $1.27(1.04-1.54)$ & $1.68(1.25-2.26)$ & $1.46(1.13-1.88)$ \\
\hline & Secondary education or more & $1.13(0.88-1.44)$ & $1.64(1.06-2.57)$ & $1.29(0.92-1.81)$ \\
\hline \multirow[t]{2}{*}{ Self rated health } & Very good/good & 1 & 1 & 1 \\
\hline & Fair/poor/very poor & $0.91(0.76-1.08)$ & $0.17(0.11-0.25)$ & $0.16(0.12-0.22)$ \\
\hline \multirow[t]{3}{*}{$\mathrm{Na}^{\mathrm{a}}$ of chronic conditions } & None & 1 & 1 & 1 \\
\hline & 1 & $1.10(0.87-1.37)$ & $1.45(0.95-2.20)$ & $1.52(1.06-2.16)$ \\
\hline & $\geq 2$ & $1.13(0.88-1.44)$ & $1.12(0.75-1.66)$ & $0.97(0.68-1.38)$ \\
\hline \multirow[t]{3}{*}{ Number of medications } & None & 1 & 1 & 1 \\
\hline & 1 & $1.00(0.76-1.32)$ & $1.25(0.57-2.71)$ & $0.63(0.35-1.15)$ \\
\hline & $\geq 2$ & $0.89(0.66-1.18)$ & $0.35(0.18-0.71)$ & $0.33(0.19-0.59)$ \\
\hline \multirow[t]{3}{*}{ BMl } & Normal & 1 & 1 & 1 \\
\hline & Overweight & $1.00(0.84-1.22)$ & $1.40(1.02-1.91)$ & $1.08(0.83-1.41)$ \\
\hline & Obesity & $0.66(0.43-0.96)$ & $0.92(0.62-1.36)$ & $0.70(0.51-0.98)$ \\
\hline \multirow[t]{3}{*}{ Smoking habits } & Smoker & 1 & 1 & 1 \\
\hline & Ex Smoker & $0.90(0.72-1.13)$ & $0.54(0.33-0.87)$ & $0.95(0.66-1.36)$ \\
\hline & Non Smoker & $0.79(0.62-1.02)$ & $0.66(0.39-1.12)$ & $1.41(0.95-2.09)$ \\
\hline \multirow[t]{2}{*}{ Sleep habits (hours/day) } & $<8$ & 1 & 1 & 1 \\
\hline & $\geq 8$ & $0.99(0.84-1.17)$ & $1.24(0.93-1.65)$ & $1.27(1.00-1.60)$ \\
\hline \multirow[t]{6}{*}{ SNHS } & 1987 & 1 & - & - \\
\hline & 1993 & $2.51(2.03-3.11)$ & 1 & 1 \\
\hline & 1995-97 & $3.35(2.65-4.23)$ & $1.01(0.57-1.78)$ & $0.81(0.51-1.26)$ \\
\hline & 2001 & $3.76(3.04-4.66)$ & $1.35(0.89-2.02)$ & $0.96(0.69-1.35)$ \\
\hline & 2003 & $1.99(1.62-2.45)$ & $1.18(0.80-1.74)$ & $1.01(0.73-1.41)$ \\
\hline & 2006 & $4.22(2.85-5.59)$ & $1.09(0.74-1.62)$ & $0.81(0.58-1.13)$ \\
\hline
\end{tabular}

The results of the logistic models are shown as adjusted odds ratios (ORs) with $95 \%$ confidence intervals. Models adjusted by all variables shown in the table, no significant interactions were found.

decrease in PA among studies may be related to the definition and measurement of LTPA and physical fitness [18], study designs, or the statistical analysis [51]. In the current study, we used a self-reported measure of PA including two questions with 2 possible answers, which can have limited the assessment of activity and exercise. Additionally, the SNHS only assessed LTPA and PA; therefore, we cannot examine occupational, recreational, and transport-related PA independently. In addition, the validity of the questions included in the surveys have not been analyzed. The use of objective measures could complement self-report data to avoid bias, i.e., quantification of physical activity level by calculating MET or using accelerometers [27]; however, this is not generally feasible in large-scale population surveys due to extensive costs. Further, even when individuals can overestimate their participation in exercise, and underestimate sedentary behaviors [14,18], surveys are extremely useful for investigating patterns, frequencies, and time trends. Finally, the use of objective measurements for assessing PA has changed over the last years, so the use of the same outcome for 20 years is difficult. Secondly, the study design does not permit to establish a cause and effect relationship due to the lack of longitudinal follow-up of the same individuals. Nevertheless, the use of a national populationbased survey permits the inclusion of representative national sample sizes. Despite these limitations this study provides additional insight into demographic aspects of LTPA and physical fitness in older adults for whom there is little information at population levels, particularly in Spain. 


\section{Conclusion}

Our study revealed an increase in LTPA, but not in physical fitness, from 1987 to 2006 in older Spanish people. Older people (age $\geq 80$ years), married, with a greater number of co-morbid chronic conditions and obese exhibited a relatively lower LTPA. Similarly, older people (age $\geq 80$ years, those taking a greater number of medications for chronic conditions, obese, and with worse self-perceived health status tended to have a relatively lower physical fitness. These results have potential implications for health services, as identification of these factors can help to prevent physical inactivity and improve the health status of older people in Spain

\section{List of abbreviations}

PA: Physical activity; LTPA: Leisure time physical activity; SNHS: The Spanish National Health Surveys; ORs: Odds ratios.

\section{Acknowledgements and funding}

None

\section{Author details}

1 Department of Health Science II, Universidad Rey Juan Carlos, Madrid, Spain ${ }^{2}$ Preventive Medicine and Public Health Teaching and Research Unit, Department of Health Sciences, Universidad Rey Juan Carlos, Madrid, Spain. ${ }^{3}$ School of Public Health. Madrid. Spain. ${ }^{4}$ Department of Physical Therapy, Occupational Therapy, Rehabilitation and Physical Medicine, Universidad Rey Juan Carlos, Alcorcón, Madrid, Spain.

\section{Authors' contributions}

DPC conceived of the study, and participated in its design and coordination and draft the manuscript. CAB carried out the acquisition of the data, analysis and interpretation of data. She has been involved in revising it critically. VHB participated in the design of the study and performed the statistical analysis. PCG carried out the acquisition of the data, analysis and interpretation of data. She has been involved in revising it critically. RJG participated in the design of the study and performed the statistical analysis. EPM carried out the acquisition of the data, analysis and interpretation of data. She has been involved in revising it critically. CFP conceived of the study, and participated in its design and coordination and helped to draft the manuscript.

All authors read and approved the final manuscript.

\section{Authors' information}

None

\section{Competing interests}

The authors declare that they have no financial competing interests and non-financial competing interests.

Conflict of interest: The manuscript, or parts of it, have not been and will not be submitted elsewhere for publication.

Role of the funding source: We have not financial interest and we have not received direct $\mathrm{o}$ indirect funding, and there is not conflict of interest.

Received: 15 June 2011 Accepted: 13 October 2011

Published: 13 October 2011

\section{References}

1. United Nations: Population Division: World Population Ageing 1950-2050. New York: United Nations; 2002.

2. Christensen K, Doblhammer G, Rau R, Vaupel JW: Ageing populations: the challenges ahead. Lancet 2009, 374:1196-1208.

3. Prohaska T, Belansky E, Belza B, Buchner D, Marshall V, McTigue K, Santariano W, Wilcox S: Physical activity, public health, and aging: Critical issues and research priorities. J Gerontol B Psychol Sci Soc Sci 2006, 6: S352-S356.

4. Elsawy B, Higgins KE: Physical activity guidelines for older adults. Am Fam Physician 2010, 81:55-9.

5. Gregg EW, Cauley JA, Stone K, Thompson TJ, Bauer DC, Cummings SR, Ensrud KE: Study of Osteoporotic Fractures Research Group: Relationship of changes in physical activity and mortality among older women. J Am Med Dir Assoc 2003, 289:2379-86.

6. Hirsch $C H$, Diehr $P$, Newman AB, Gerrior SA, Pratt C, Lebowitz MD, Jackson SA: Physical Activity and Years of Healthy Life in Older Adults: Results From the Cardiovascular Health study. J Aging Phys Activity 2010, 18:313-334.

7. Boyle PA, Buchman AS, Wilson RS, Bienias $J$, Bennett DA: Physical activity is associated with incident disability in community-based older persons. J Am Geriatr Soc 2007, 55:195-201.

8. Byberg L, Melhus H, Gedeborg R, Sundström J, Ahlbom A, Zethelius B, Berglund LG, Wolk A, Michaëlsson K: Total mortality after changes in leisure time physical activity in 50 year old men: 35 year follow-up of population based cohort. BMJ 2009, 338:b688.

9. Ueshima K, Ishikawa-Takata K, Yorifuji T, Suzuki E, Kashima S, Takao S, Sugiyama M, Ohta T, Doi H: Physical activity and mortality risk in the Japanese elderly: a cohort study. Am J Prev Med 2010, 38:410-8.

10. Stessman J, Hammerman-Rozenberg R, Cohen A, Ein-Mor E, Jacobs JM: Physical activity, function, and longevity among the very old. Arch Intern Med 2009, 169:1476-83.

11. Demakakos P, Hamer M, Stamatakis E, Steptoe A: Low-intensity physical activity is associated with reduced risk of incident type 2 diabetes in older adults: evidence from the English Longitudinal Study of Ageing. Diabetologia 2010, 53:1877-85.

12. Motl RW, McAuley E: Physical activity, disability, and quality of life in older adults. Phys Med Rehabil Clin N Am 2010, 21:299-308.

13. Caspersen CJ, Powell KE, Christenson GM: Physical Activity, Exercise, and Physical Fitness: Definitions and Distinctions for Health-Related Research. Public Health Rep 1985, 100:126-131.

14. Ashe MC, Miller WC, Eng JJ, Noreau L: Physical Activity and Chronic Conditions Research Team: Older adults, chronic disease and leisuretime physical activity. Gerontology 2009, 55:64-72.

15. Centers for Disease Control and Prevention: Physical activity and health A report of the Surgeon General. Atlanta: US Dept of Health and Human Services; 1996 [http://www.cdc.gov/nccdphp/sgr/chap2.htm].

16. Lim K, Taylor L: Factors associated with physical activity among older people- a population-based study. Prev Med 2005, 40:33-40.

17. Jurj AL, Wen W, Gao YT, Matthews CE, Yang G, Li HL, Zheng W, Shu XO: Patterns and correlates of physical activity: a cross-sectional study in urban Chinese women. BMC Public Health 2007, 7:213.

18. Merom D, Bowles $H$, Bauman A: Measuring Walking for Physical Activity Surveillance- The effect of Prompts and Respondents' Interpretation of Walking in a Leisure-Time Survey. J Phys Activity Health 2009, 6:S81-S88.

19. Fors S, Lennartsson C, Lundberg O: Health inequalities among older adults in Sweden 1991-2002. Eur J Public Health 2008, 18:138-43.

20. Murabito JM, Pencina MJ, Zhu I, Kelly-Hayes M, Shrader P, D'Agostino RB Sr: Temporal trends in self-reported functional limitations and physical disability among the community-dwelling elderly population: the Framingham Heart Study. Am J Public Health 2008, 98:1256-62.

21. Allman-Farinelli MA, Chey T, Merom D, Bowles H, Bauman AE: The effects of age, birth cohort and survey period on leisure-time physical activity by Australian adults: 1990-2005. Br J Nutr 2009, 101:609-617.

22. Bromley C, Sproston K, Shelton N: The Scottish Health Survey 2003. Adults. Scotland: Scottish Executive 2005, 2: [http://www.scotland.gov.uk/Resource/ Doc/76169/0019729.pdf]

23. Carlson SA, Densmore D, Fulton JE, Yore MM, Kohl HW: Differences in Physical Activity Prevalence and Trends From 3 U.S. Surveillance Systems: NHIS, NHANES, and BRFSS. J Phys Activity Health 2009, 6:S18-S27.

24. Center for Disease Control: Trends in leisure-time physical inactivity by age, sex, and race/ethnicity-Unites Sates, 1994-2004. MMWR 2005, 54:991-994.

25. Kurozawa $Y$, Hosoda T, Iwai N, Nose T, Yoshimura T, Tamakoshi A, for the JACC Study Group: Levels of Physical Activity among Participants in the JACC Study. J Epidemiol 2005, 15:S43-S47. 
26. Orsini N, Bellocco R, Bottai M, Pagano M, Wolk A: Age and Temporal Trends of Total Physical Activity among Swedish Women. Med Sci Sports Exerc 2006, 240-5.

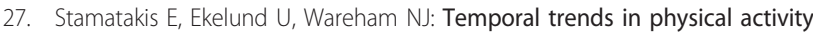
in England: The health Survey for England 1991 to 2004. Prev Med 2007, 45:416-423.

28. Simpson ME, Serluda M, Galuska DA, Gillespie C, Donehoo R, Macera C, Mack K: Walking Trends Among U. S. Adults. The Behavioral Risk Factors Surveillance System, 1987-2000. Am J Prev Med 2003, 25:95-100.

29. Kaplan MS, Newson JT, McFarland BH, Lu L: Demographic and psychosocial correlates of physical activity in late life. Am J Prev Med 2001, 21:306-312.

30. Knuth AG, Hallal PC: Temporal trends in Physical Activity: A Systematic review. J Phys Act Health 2009, 6:548-559.

31. Lindström M, Isacsson SO, Merlo J: Increasing prevalence of overweight, obesity and physical inactivity: Two population-based studies 1986 and 1994. Eur J Public Health 2003, 13:306-312

32. Pan SY, Cameron C, DesMeules M, Morrison H, Craig CL, Jiang XH: Individual, social, environmental, and physical environmental correlates with physical activity among Canadians: a cross-sectional study. BMC Public Health 2009, 9:21.

33. Wong $\mathrm{CH}$, Wong SF, Shen L: Correlates of Habitual Walking and Sports/ Leisure-time Physical Activity in Older Persons in Singapore: Interaction Effects Between Educational Attainment and Gender. Ann Acad Med Singapore 2003, 32:801-6

34. Guallar-Castillón P, Santa-Olalla Peralta P, Banegas JR, López E, RodríguezArtalejo F: Physical activity and quality of life in older adults in Spain. Med Clin (Barc) 2004, 123:606-10.

35. López-García E, Banegas-Banegas JR, Gutiérraz-Fisac JL, Graciani PérezRegadera A, Díez Gañán L, Rodríguez-Artalejo F: Relation between body weight and health-related quality of life among the elderly in Spain. Int J Obes Relat Metab Disord 2003, 27:701-9.

36. Rodríguez-Artalejo F, López García E, Gutiérrez-Fisac JL, Banegas Banegas JR, LaFuente Urdinguio P, Domínguez Rojas V: Changes in the prevalence of overweight and obesity and their risk factors in Spain, 1987-1997. Prev Med 2002, 34:72-811.

37. Garatachea N, Molinero O, Martínez-García R, Jiménez-Jiménez R, GonzálezGallego J, Márquez S: Feelings of well being in elderly people: relationship to physical activity and physical function. Arch Gerontol Geriatr 2009, 48:306-1.

38. Instituto Nacional de Estadística: panish National Health Survey 2006. Madrid, Spain: Spanish Goverment; 2006 [http://www.msc.es/estadEstudios/ estadisticas/encuestaNacional/encuesta2006.htm]

39. Ministerio de Sanidad y Consumo: Spanish National Health Survey 19872003. Madrid, Spain: Ministerio de Sanidad y Consumo; 2004 [http://www. msps.es/estadEstudios/estadisticas/estadisticas/microdatos/ frmBusquedaMicrodatos.jsp].

40. Román-Viñas B, Serra-Majem L, Ribas-Barba L, Roure-Cuspinera E, Cabezas C, Vallbona C, Plasencia A: Trends in physical activity status in Catalonia, Spain (1992-2003). Public Health Nutr 2007, 10:1389-1395.

41. Cornelio Cl, García M, Schiaffino A, Borrás JM, Nieto FJ, Fernández E, for the CHIS.FU Study Group: Changes in leisure time and occupational physical activity over 8 years: the Cornellá Health Interview Survey Follow-Up Study. J Epidemiol Community Health 2008, 62:239-244.

42. Gallant MP, Dorn GP: Gender and race differences in the predictors of daily health practices among older adults. Health Educ Res 2001, 16:21-31.

43. Krause MP, Januário RSB, Hallage T, Haile L, Miculis CP, Gama MPR, Goss FL, da Silva SGA: A comparison of Functional Fitness of Older Brazilian and American Women. J Aging Phys Act 2009, 17:387-397.

44. Mathews AE, Laditka SB, Laditka JN, Wilcox S, Corwin SJ, Liu R, Friedman DB, Hunter R, Tseng W, Logsdon RG: Older adults' perceived physical activity enablers and barriers: a multicultural perspective. $J$ Aging Phys Act 2010, 18:119-40.

45. Varo-Cenarruzabeitia JJ, Martínez-González MA, Sánchez-Villegas A, Martínez-Hernández JA, Irala-Estévez JJ, Gibney MJ: Attitudes and practices regarding physical activity: situation in Spain with respect to the rest of Europe. Aten Primaria 2003, 31:77-84

46. Stenholm S, Rantanen T, Alanen E, Reunanen A, Sainio P, Koskinen S: Obesity history as a predictor of walking limitation at old age. Obesity 2007, 15:929-938.
47. Stenholm S, Alley D, Bandinelli S, Griswold ME, Koskinen S, Rantanen T, Guralnik JM, Ferrucci L: The effect of obesity combined with low muscle strength on decline in mobility in older persons: results from the InCHIANTI Study. Int J Obes 2009, 33:635-644.

48. Chad K, Reeder BA, Harrison EL, Ashworth NL, Sheppard SM, Schultz SL, Bruner BG, Fisher KL, Lawson JA: Profile of physical activity levels in community-dwelling older adults. Med Sci Sports Exerc 2005, 37:1774-84.

49. Wilcox S, Sharkey JR, Mathews AE, Laditka JN, Laditka SB, Logsdon RG, Sahyoun N, Robare JF, Liu R: Perceptions and beliefs about the role of physical activity and nutrition on brain health in older adults. Gerontologist 2009, 49:561-71.

50. Leavy B, Aberg AC: "Not ready to throw in the towel": perceptions of physical activity held by older adults in Stockholm and Dublin. J Aging Phys Act 2010, 18:219-36.

51. Wadsworth LA, Johnson CP: Mass media and healthy aging. J Nutr Elder 2008, 27:319-31

52. Gooberman-Hill R, Ebrahim S: Making decisions about simple interventions: older people's use of walking aids. Age Ageing 2007, 36:569-73

53. Ayotte BJ, Margrett JA, Hicks-Patrick J: Physical activity in middle-aged and young-old adults: the roles of self-efficacy, barriers, outcome expectancies, self-regulatory behaviors and social support. $J$ Health Psychol 2010, 15:173-85.

54. McAuley E, May KS, Motl RW, White SM, Wójcicki TR, Hu L, Doerksen SE: Trajectory of Declines in Physical Activity in Community-Dwelling Older Women: Social Cognitive Influences. J Gerontol B Psychol Sci Soc Sci 2009 64:543-50

\section{Pre-publication history}

The pre-publication history for this paper can be accessed here: http://www.biomedcentral.com/1471-2458/11/799/prepub

\section{doi:10.1186/1471-2458-11-799}

Cite this article as: Palacios-Ceña et al:: Time trends in leisure time physical activity and physical fitness in elderly people: 20 year followup of the Spanish population national health survey (1987-2006). BMC Public Health 2011 11:799.

\section{Submit your next manuscript to BioMed Central and take full advantage of:}

- Convenient online submission

- Thorough peer review

- No space constraints or color figure charges

- Immediate publication on acceptance

- Inclusion in PubMed, CAS, Scopus and Google Scholar

- Research which is freely available for redistribution 